https://doi.org/10.31426/ijamsr.2018.1.4.212

I J A M S R

International Journal of

Advanced Multidisciplinary Scientific Research (IJAMSR) ISSN:2581-4281

\title{
CONTRIBUTION OF EDUCATION ON STANDARD OF LIVING
}

\section{Dr Sayantani Roy Choudhury, Ms Bishaka Agarwal,}

Assistant Professor, Amity School of Economics, Amity University, Kolkotta, India

Post Graduate Student, Amity University, Kolkotta, India.

srchoudhury@kol.amity.edu

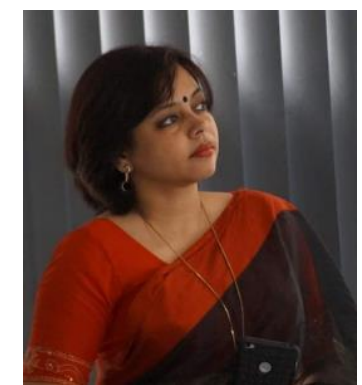

DR.SAYANTHI ROY CHOWDARY

\begin{abstract}
A B S T R A C T
This paper estimates returns to education in India using a nationally representative survey. The paper has taken worldwide secondary data from Human Development Report (HDR) 2015 containing the HDIs of all 188 countries compiled in total as well as been segregated under their three HDI slabs, i.e. High, Medium, Low HDI Countries respectively. We try to analyze the contribution of education on standard of living based on the theory, an increase in education implies an increase in employment that further indicates the rise in income and then an increase in the consumption level. Here, consumption is taken as an indicator of standard of living.
\end{abstract}

Citation: Dr Sayantani Roy Choudhury, Ms Bishaka Agarwal (2018). Contribution Of Education On Standard Of Living. International Journal of Advanced Multidisciplinary Scientific Research (IJAMSR) ISSN:2581-4281 Vol 1, Issue4, June 2018, \#Art.212, pp11-24

question let us go back to 1960's when Theodore Schultz, an American Economist invented the term "human capital" to reflect the value of human capacities. Thus, one has a surprising degree of control over one's human capital, unlike the financial markets. We can switch jobs, obtain graduate degrees or simply work more as an independent contractor or partner in a professional firm. So we can consider human capital a measurable return on investment — in oneself. bring to the table that can have the most impact on one's future. But what this Human Capital actually is that plays such a major role in one's future? To answer this 


\section{International Journal of Advanced Multidisciplinary Scientific Research (IJAMSR) ISSN:2581-4281}

The stodgy economist's definition of human capital is the net present value of lifetime earnings. This is what we will earn based on the skills, experience and talent we contribute to the labor market. For some, this is a fixed quantity, but in a dynamic world where people are increasingly shifting careers, working longer or pursuing "encore" careers, human capital is a moving target.

Yet estimating human capital is a bit like trying to guess your life expectancy. Life throws us a lot of curves and income gauges look easy to calculate as they emerge from a software program. Nevertheless, we need to do some projections of lifetime earnings, and potential changes in our income stream, to make a realistic, flexible and holistic financial plan.

Figuring human capital into a prudent financial plan requires an attention to detail that most financial advisers may not be able to handle. Paula Hogan, a fee-only certified financial planner based in Milwaukee, has been employing human capital and the life-cycle theory that underpins it into her business model for years. Like most planners, she carefully examines cash flow, expenses, income and her client's portfolio.

Poverty entails lack of empowerment, lack of knowledge and lack of opportunity as well as lack of income and capital. In the less developed or developing countries the poor families become impoverished due to lack of proper food, financial capital and education. Families that live in extreme poverty often see school as an impossible cost. The Even public school carries costs, including books, uniforms, and transportation. Because parents have not experienced the increases in earnings, quality of life, and personal dignity that come from education, they don't know what they are missing by pulling a child out of school to work instead. This is why it's a cycle: children who grow up without education are less likely to send their own children to school. Also, due to lack of knowledge or too much conflicting information on diet and health, lack of motivation, accessibility and income, these low income groups have a greater tendency to consume unbalanced diets and have low intakes of fruit and vegetables, thus there is a lack of nutrients required for the increased needs of mothers and babies resulting in increased health risk for these the mothers and their babies. Therefore, poor health and education leads to unemployment and that further leads to low income, low consumption and low productivity. This low productivity again leads to lower employment and poverty. This goes on like a circle leading to a vicious cycle of poverty. Therefore, in economics, the cycle of poverty is the "set of factors or events by which poverty, once started, is likely to continue for atleast three generations i.e. for enough time that the family includes no surviving ancestors who possess and can transmit the intellectual, social, and cultural capital necessary to stay out of or change their impoverished condition, unless there is outside intervention". This intervention is needed in the form of a Big Push where Government's interference plays an important role in investing in the generation of human capital.

The main obstacle to economic growth is the backwardness of human power. Thus, to overcome this obstacle there is a need to increase the skill of human power through the enhancement or widening of education, technical knowledge and administrative training. Also, health facilities should be enhanced which may increase the efficiency of the workers. According to the reports of UNICEF, more than two decades of experience in development and emergency 


\section{International Journal of Advanced Multidisciplinary Scientific Research (IJAMSR) ISSN:2581-4281}

response have shown that investing on education can make a lasting difference that is not just good for children but it's good for the nations as well. Investing in education isn't just the right thing to do, it's smart economics.

Education can put people on a path towards good health, empowerment and employment. It can help to build happier societies. And the benefits of girls' education extend to their own children who are often healthier and more educated because their mothers went to school.

Evidence shows that, on average, each additional year of education boosts a person's income by 10 per cent and increases a country's GDP by 18 per cent. Some researchers estimate that if every child learned to read, around 170 million fewer people would live in poverty.

In his book Children in Jeopardy: Can We Break the Cycle, Irving B. Harris discusses ways in which children can be helped to begin breaking the cycle of poverty. He stresses the importance of starting early and teaching children the importance of education from a very young age as well as making sure these children get the same educational opportunities as students who are richer. Family values such as nurturing children and encouraging them to do well in school need to be promoted as well as a non-authoritarian approach to parenting. Harris also discusses the importance of discouraging teenage pregnancy and finding ways in which to decrease this phenomenon so that when children are born, they are planned and wanted and thus have a better chance at breaking the cycle of poverty. 


\section{International Journal of Advanced Multidisciplinary Scientific Research (IJAMSR) ISSN:2581-4281}

macroeconomic results, like increasing the income which in turn raises the consumption which is found directly or indirectly in living conditions and well being. Thus, education contributes to quality of life, both individually and at the society level.

In this context, the education that young people should receive becomes an essential pillar in the economic recovery process, along with the importance that needs to be given to increasing the compatibility between the type of education and labor market needs. However, in the developing or least developed countries, individuals have low income so uncertainty increases, revenue decreases and individuals will invest less in education, which will have negative long term implications because individuals will be facing difficulties in finding work, having social integration problems and the chance to send this to their children is very high. This will have a negative impact on the standard of living. Therefore, measures need to be taken and implemented to encourage investment in retraining and continuous training, both through programs at company level and at the governmental level. Also, reduction in inequality is needed by improving the employment perspectives of those most in need, including the disadvantaged and the immigrants for a better well- being of any nation.

\section{Literature Review}

There is extensive literature on returns to education or schooling for both developed and developing countries. Despite huge increases in education in developing countries after 1960 the accompanying increases in production have been disappointing, prompting Pritchett (2001) to ask "where has all the education gone?" It is very important to answer this question. In the growth literature, there seems to be a relationship between the level of education and subsequent growth (Barro, 1991) although Bils and Klenow (2000) suggest that the causal relationship need not run from education to grow. A more educated population may cause higher growth for everyone, even if the better educated cohorts do not benefit more Education may contribute to a more desirable civic society, may improve health, and may be valuable in its own right (Sen, 1999). Education, particularly for women, may also lead to a more equitable distribution across society and within the family. With a population of more than a billion people and large increases in education, the overall returns to education in developing countries like India are important by themselves, but India's diverse states provide an additional way to examine what drives the returns to education. For example, Foster and Rosenzweig (1996) find that returns increased in areas where the Green Revolution allowed the use of new technologies. Yet, the returns at the cohort level do not seem to vary substantially at the state level. One reason the returns may be so low, especially in the medium and low HDI countries is that the quality of education may be poor (PROBE Team (1999)). Most studies of the returns to education worldwide, especially in developing countries consider only wage rates, which means that they apply only to a very small, almost entirely male and urban, 4 sections of the population. Duraisamy (2002) uses the employment rounds of the National Sample Survey (NSS) in 1983 and 1993-1994 to estimate a Mincerian regression of log wages on education for individuals. Education and inequality are also closely linked. Kijima (2006) finds increasing returns at the higher education levels after 1991, and uses this increase to explain rising inequality in India. 


\section{International Journal of Advanced Multidisciplinary Scientific Research (IJAMSR) ISSN:2581-4281}

In general, Social returns to education are lower than private returns because education is publicly subsidized in most countries and also due to the fact that estimates of social returns are not able to include social benefits of education. The rates of return to education vary significantly from country to country and also within a country over time. The returns are higher in the lowincome (sub-Saharan African) and middle-income (Latin American/Caribbean) countries and are lower in the high-income (OECD) countries. Psacharopoulos (1985, 1994); showed that the phenomenon could be due to differences in the relative scarcity of human to physical capital within each group of countries. This may be due to 'complementarity' between ability and education; if persons with higher ability earn 4 more the returns to those in the top deciles of the wage distribution would be higher (Harmon et al., 2003).

The returns to education also vary by the nature of employment or work contract. Dutta (2006) finds a significant difference in the returns between casual and regular male workers using three rounds of the NSSO survey. While those in the former category face 'flat' returns, those in the latter category have positive and ' $U$ shaped' returns with respect to levels of education. These patterns indicate that with regard to consumption, education is important in two respects (Wiley Blackwell journal, 2015). With regard to consumption, education is important in two respects (Wiley Blackwell journal, 2015). First, consumer education means the teaching of the different skills, knowledge, and norms that are important for achieving a consumer's different goal. The second aspect is the empirical and theoretical relationship between certain measurements of education (e.g., years of schooling) and different forms of consumption. There are studies on education and its impact on general consumption orientations (e.g., delay of gratification), and in specific fields of consumption, like food, culture, and ethical consumption, where empirical research shows that education shapes consumption to a considerable degree and theoretical explanations of this impact are discussed. (Leo Wolman, 1929) in his paper has placed notions on the standard of living at almost the center of current economic thinking with respect to the United States. The observed revolution in the things people buy and use in this country has directed attention to the neglected problems of consumption and has revived in a new guise traditional theory of economic progress. There are many now who are not content to describe changing standards, but who find in them the source and mechanism of still further improvement through real earnings, or money earnings corrected for changes in prices. They may be further described as measures, of the purchasing power of money earned. They purport, usually, to show the amount of a fixed budget that can, from time to time, be purchased with a given money income. They reveal the degree to which money income lags behind changing prices or precedes them, and are, accordingly, regarded as indicative of the losses or gains in material standards sustained by the members of various income groups.

In the literature, there are numerous contributions in the field of quality of life, highlighting the link between education, employment and welfare. Among the foreign authors we mention Blanchflower and Oswald (2004), who analyze welfare as the support of quality of life; Moretti (2004), who analyses the benefits of investment 


\section{International Journal of Advanced Multidisciplinary Scientific Research (IJAMSR) ISSN:2581-4281}

in higher education; Ferrante (2009), who explains the connection between education and life satisfaction; and Greenhaus, Collins and Shaw (2003) highlight the link between work, family and quality of life. Thus, in analyzing the quality of life, both at the individual and the society level. The people's ultimate objective is happiness and the money is only one of many ways to increase overall life satisfaction (Andren and Martinsson, 2006). Thus, quality of life can be taken into account by taking into account many factors such as job satisfaction, living conditions, education, infrastructure, etc. In analyzing the indicators on the quality of life, it is also important knowing the individual preferences and perceptions, that cannot be seen directly, but require a number of indirect observation methods (ŞerbanOprescu, 2011).

Among the organizations that analyze the quality of life in different countries, ranking them, there are OECD (Better Life Index), The Economist Intelligence Unit (Quality of life index), Eurofound (Quality of Life Survey), European Bank for Reconstruction and Development (Report of Life Satisfaction), Legatum Institute London, UK (The 2011 Legatum Prosperity Index), European Commission (Well Being-Aggregate Report). Even if these organizations often apply different methodologies and different take into account different sub-indicators to explain the main indicators of quality of life, the results obtained show similar classification of the countries analyzed.

\section{Objective}

To develop, nation-wide or at the individual level, more education is obviously one of the main factors. To find out how much a person is getting from education, I have taken worldwide secondary data from Human
Development Report (HDR) 2015. HDR is a representative series of global Human Development Reports published by the United Nations Development Program (UNDP) since 1990 as independent, analytically and empirically grounded discussions of major development issues, trends and policies in 200 countries with 188 countries being segregated under the three HDI slabs, i.e. High, Medium, Low HDI Countries respectively.

To validate this data set containing the HDIs of the 188 countries, we divide the research questions into two parts namely:

1. To analyze whether there is a positive relationship between:

i) Education and Employment by setting the linear regression equation as:

Employment $=\alpha_{1}+\beta_{1}$ (education); where employment is the dependent variable, education is the independent variable and $\alpha_{1} \& \beta_{1}$ are the OLS coefficients.

To check the significance level of the relationship we do hypothesis testing by setting the null hypothesis as $\mathrm{H}_{0}$ : $\beta_{1}=0$ and alternate hypothesis as $\mathrm{H}_{1}: \beta_{1} \neq 0$

ii) Employment and Income by again setting the linear regression equation as:

Income $=\alpha_{2}+\beta_{2}$ (employment); where income is the dependent variable, employment is the independent variable and $\alpha_{2} \& \beta_{2}$ being the OLS coefficients.

To check the significance level of the relationship we do hypothesis testing by setting the null hypothesis as $\mathrm{H}_{0}$ : $\beta_{2}=0$ and alternate hypothesis as $\mathrm{H}_{1}: \beta_{2} \neq 0$ 


\section{International Journal of Advanced Multidisciplinary Scientific Research (IJAMSR) ISSN:2581-4281}

iii) Income and Consumption by setting the linear regression equation as:

Consumption $=\alpha_{3}+\beta_{3}$ (income); where employment is the dependent variable, education is the independent variable and $\alpha_{3} \& \beta_{3}$ are the OLS coefficients.

To check the significance level of the relationship we do hypothesis testing by setting the null hypothesis as $\mathrm{H}_{0}$ : $\beta_{3}=0$ and alternate hypothesis as $\mathrm{H}_{1}: \beta_{3} \neq 0$

2. To compare the three sets of countries by categorizing the countries according to their Human Development Index.

\section{Methodology}

1. I have taken a secondary data set for Human Development Report 2015 containing the HDIs of all countries compiled in total as well as categorically. Sample size $=188$.

2. Statistical tools used for validating the objectives of the research are: chi square test for comparison of means along with correlation and regression analysis. For authentication of this analysis, hypothesis testing is done using $\mathrm{t}$ - test.

\section{Analysis}

Analyzing the relationship between the following variables we find that: i) Education and Employment by setting the linear regression equation as:

Employment $=\alpha_{1}+\beta_{1}$ (education); where employment is the dependent variable, education is the independent variable and $\alpha_{1}, \beta_{1}$ are the OLS coefficients.

\section{Result}

We got a statistically significant value of correlation coefficient as- 0.325

It implies the alternative hypothesis is true and employment is inversely related to education.

ii) Employment and Income by again setting the linear regression equation as:

Income $=\alpha_{2}+\beta_{2}$ (employment); where income is the dependent variable, employment is the independent variable and $\alpha_{2}, \beta_{2}$ are the OLS coefficients.

\section{Result}

We got a statistically significant value of correlation coefficient as- 0.055

It implies the alternative hypothesis is true and income is inversely related to employment.

iii) Income and Consumption by setting the linear regression equation as:

Consumption $=\alpha_{3}+\beta_{3}$ (income); where employment is the dependent variable, education is the independent variable and $\alpha_{3}, \beta_{3}$ are the OLS coefficients. 


\section{International Journal of Advanced Multidisciplinary Scientific Research (IJAMSR) ISSN:2581-4281}

\section{Result}

We got a statistically significant value of correlation coefficient as 0.083

It again implies that the alternative hypothesis is true and consumption is positively related to income.

\section{Interpretation Based On The Result}

Hence, we got a result which is not going with the theory. According to the theory, an increase in education implies an increase in employment that further indicates the rise in income and then an increase in the consumption level. Therefore, we have to explore the reason behind that result. For that we segregate the countries according to their HDI ranks (Human Development Report). Now if we decompose the countries according to the HDIs, we find that

\section{Correlation Coefficient}

\begin{tabular}{|l|l|l|l|l|}
\hline Paramete & Worldwid & $\begin{array}{l}\text { High Hdi } \\
\text { rs }\end{array}$ & $\begin{array}{l}\text { Medium } \\
\text { Countries } \\
\text { Cdi } \\
\text { Countries }\end{array}$ & $\begin{array}{l}\text { Low Hdi } \\
\text { Countries }\end{array}$ \\
\hline Educatio & & & & \\
$\mathrm{n}:$ & & & & \\
Employm & - & & - & - \\
ent & 0.325807 & 0.029206 & 0.152852 & 0.013565 \\
& $711^{*}$ & $221^{*}$ & $167^{*}$ & $432^{*}$ \\
\hline Employm & & & & \\
ent: & - & & & - \\
Income & 0.055633 & 0.356084 & 0.049169 & 0.468516 \\
\hline Income: & $194^{*}$ & $818^{*}$ & $575^{*}$ & $579^{*}$ \\
Consump & & & & \\
tion & 0.083113 & 0.043801 & 0.043077 & 0.063825 \\
\hline
\end{tabular}

- Education and Employment are inversely related specifically in case of Medium and Low HDI countries.

- Employment and income are negatively related only in case of Low HDI countries.

- More surprisingly, Income and Consumption are having an inverse relationship and that too only in case of Medium HDI countries.

Therefore, the negative pool from Medium and Low HDI countries made the world wide relationship between education and employment negative. Similarly, a strong negative pool from only Low HDI countries had an inverse relationship between employment and income for the entire world, On the other hand, though income and consumption share a negative relationship in Medium HDI countries, its impact is not as huge to make the worldwide relationship of the same variables to be negative.

To analyze further, we form a model as given below:

Consumption $=\mathrm{a}+\mathrm{b}_{1}($ education $)+\mathrm{b}_{2}$ (income $)+\mathrm{b}_{3}$ (employment) $+\mathrm{b}_{4}$ (inequality)

We do regression analysis with this model separately for High, Medium and Low HDI countries. 
https://doi.org/10.31426/ijamsr.2018.1.4.212

I J A M S R

\section{International Journal of}

Advanced Multidisciplinary Scientific Research (IJAMSR) ISSN:2581-4281

\section{Regression Tables Categorically Are Given Below:}

\section{High HDI Countries}

Anova

Table 1 (high HDI)

\begin{tabular}{|l|l|l|l|l|l|}
\hline Model & $\begin{array}{l}\text { Sum of } \\
\text { Squares }\end{array}$ & $\begin{array}{l}\text { Mean } \\
\text { Squar } \\
\text { e }\end{array}$ & F & Sig. \\
\hline Regressio & 180.751 & 4 & 45.188 & 1.34 & .25 \\
n & 3359.09 & $\begin{array}{l}10 \\
0\end{array}$ & 33.591 & 5 & 9 \\
\hline
\end{tabular}

Table 2 (high HDI)

\begin{tabular}{|c|c|}
\hline Model & B \\
\hline (Constant) & 10.656 \\
\hline Education & $.458^{*}$ \\
\hline Income & -3.452 \\
\hline Employment & $.055^{*}$ \\
\hline Inequality in income & -.057 \\
\hline
\end{tabular}

\section{Interpretation of the above table:}

From the table, it is clearly visible that education and employment has significant influence on consumption. The influence is positive with estimated values of coefficients as $.458 \& .055$ respectively. On the other hand, for the High HDI countries consumption is seen to be not influenced by income and inequality in income significantly.

\section{Medium HDI Countries}

Anova

Table 3 (medium HDI)

\begin{tabular}{|l|l|l|l|l|l|}
\hline Model & $\begin{array}{l}\text { Sum of } \\
\text { Squares }\end{array}$ & $\begin{array}{l}\mathrm{d} \\
\mathrm{f}\end{array}$ & $\begin{array}{l}\text { Mean } \\
\text { Square }\end{array}$ & $\mathrm{F}$ & Sig. \\
\cline { 1 - 5 } $\mathrm{n}$ & 339.888 & 4 & 84.972 & $\begin{array}{l}.43 \\
6\end{array}$ & 2 \\
\cline { 1 - 4 } Residual & $\begin{array}{l}6437.33 \\
8\end{array}$ & 33 & $\begin{array}{l}195.07 \\
1\end{array}$ & & \\
\hline
\end{tabular}

Table 4(medium HDI)

\begin{tabular}{|c|c|}
\hline Model & B \\
\hline (Constant) & 30.043 \\
\hline Education & $-1.142^{*}$ \\
\hline Income & .000 \\
\hline Employment & $-.140^{*}$ \\
\hline Inequality in income & .026 \\
\hline
\end{tabular}

\section{Interpretation of the table:}

In case of the Medium HDI countries we see that consumption has a negatively significant influence with respect to education (estimated value $=-1.142$ ) and employment (estimated value $=-.140$ ). However, income and inequality in income is seen to have no significance on consumption. 


\section{International Journal of} Advanced Multidisciplinary Scientific Research (IJAMSR) ISSN:2581-4281

\section{Low HDI Countries}

\section{Anova}

Table 5 (low HDI)

\begin{tabular}{|l|l|l|l|l|l|}
\hline Model & $\begin{array}{l}\text { Sum of } \\
\text { Squares }\end{array}$ & $\begin{array}{l}\text { Mean } \\
\text { Squar } \\
\mathrm{e}\end{array}$ & $\mathrm{F}$ & Sig. \\
\cline { 1 - 5 } $\mathrm{n}$ & 337.763 & 4 & $\begin{array}{l}84.44 \\
1\end{array}$ & \multirow{2}{*}{1.28} & .29 \\
\cline { 1 - 4 } Residual & 2493.02 & 3 & $\begin{array}{l}65.60 \\
6\end{array}$ & 2 \\
\hline
\end{tabular}

Table 6 (low HDI)

\begin{tabular}{|c|c|}
\hline Model & B \\
\hline (Constant) & 15.479 \\
\hline Education & 1.193 \\
\hline Income & $-.001^{*}$ \\
\hline Employment & $-.105^{*}$ \\
\hline Inequality in income & .107 \\
\hline
\end{tabular}

Interpretation of the table:

Income and Employment significantly influence Consumption in the Low HDI countries with the estimated values are -. 001 and -. 105 respectively. These values also signify a negative relationship of these two variables with consumption. On the other hand, Consumption does not seem to be affected significantly by education and inequality in income from the above table.

\section{Further Analysis}

If we go towards exploratory research, we can use the percentage of population engaged in different sectors and the value added from the agricultural sector in the GDP.

\begin{tabular}{|l|l|l|}
\hline Mean & Std Dev & High Hdi Countries \\
\hline 5.134492 & 4.652595 & Agricultural Share \\
\hline 4.8 & 1.8 & Expenditure On Education \\
\hline 25.7 & 104.3197 & Youth Population \\
\hline
\end{tabular}

\begin{tabular}{|l|l|l|}
\hline Mean & Std Dev & Medium Hdi Countries \\
\hline 15.31637 & 8.237108 & Agricultural Share \\
\hline 5.074797 & 2.200122 & Expenditure On Education \\
\hline 38.3 & 135.095 & Youth Population \\
\hline
\end{tabular}

\begin{tabular}{|l|l|l|}
\hline Mean & Std Dev & Low Hdi Countries \\
\hline 28.56917 & 11.77907 & Agricultural Share \\
\hline 4.279415 & 2.466335 & $\begin{array}{l}\text { Expenditure On } \\
\text { Education }\end{array}$ \\
\hline 15.0 & 22.76881 & Youth Population \\
\hline
\end{tabular}




\section{International Journal of Advanced Multidisciplinary Scientific Research (IJAMSR) ISSN:2581-4281}

From the mean and standard deviation of all three categories of countries we found out that the population engaged in agricultural sector is much more in Medium (mean:15.31) and Low (mean:28.56) HDI countries than High (mean: 5.13) HDI countries.

This is because in the least developed or developing countries, despite increased access to education, the poor disproportionately women, socially disadvantaged groups, the physically disabled, persons in remote regions - are often deprived of a basic education. And when basic education is available, the poorest are unable to avail of it because the direct and opportunity costs attached to it are quite high for them. Second, the majority of these countries' poor (about 70 percent) are found in rural areas. And third, Medium HDI country like India's food security depends on producing different crops to meet the demands of a growing population with rising incomes. Thus, the majority of people go into farming just because they are poor and not because they really have a passion for it. Poverty causes agricultural growth and unemployment depends on agricultural growth. Therefore, in directly poverty causes unemployment. This can happen when people are too poor to equip themselves for the market place. For, example, as an economy modernizes and moves away from subsistent farming, poor farmers are unable to send their children to school where they can learn the skills essential for tomorrow's world: hence the parents' poverty deprives the children of opportunities and this condemns them to unemployment even as they migrate to the cities in the search of work. On a smaller scale, poverty can prevent current people from re-training themselves to remain employable in the current marketplace; therefore, poverty can create unemployment today as in if these people lose their current jobs, due to poverty and their inability to re-train themselves, they descend into unemployment. Thus, with low education these poor unskilled people that constitute approximately $70 \%$ of the total population engage in agricultural production, about $80 \%$ of the rural population is involved in the sector for employment. Hence, education share an inverse relationship with employment. Low education leads to employment majorly in agricultural sector.

Now, if we see the other side of the coin, though the expenditure on education is high, especially in the Medium HDI countries with men as 5.07 and youth population is also high in these developing countries with men as 38.3 and standard deviation as 135.095 , yet higher education does not guarantee employment. In most developing countries, governments and policy makers are increasingly finding it difficult to deal successfully with the problem of youth unemployment. As a result, a number of skills acquired from the university appear dysfunctional and irrelevant and is leading to the postponement of unemployment because of the fact that the more we are spending our time in getting ourselves highly educated, the more we are moving towards less job opportunities based on our required skill. There is a skill mismatch as, the researchers across a wide range of fields, policy makers, and large segments of the postponementlieve that the work-related the factls of the labor force do not match the requirements of jobs and that this further explains a large part of the growth of wage inequality showing an inverse relationship between employment and income that has been explained in the next part. However, from the above explained part it is again clear that education may not result in employment rather lead to voluntary unemployment. 


\section{International Journal of} Advanced Multidisciplinary Scientific Research (IJAMSR) ISSN:2581-4281

As we have already seen that in the developing countries work related skill of the labor force do not match the requirements of jobs, so either these people choose voluntary unemployment or even a doctorate chooses a clerical job leading to the growth of wage inequality. Due to infrastructural under- development the high paid employment opportunity is absent in case of Low HDI countries.

Also, as already explained above, the majority of the population in the Medium and Low HDI countries are engaged in the primary sector and agricultural production in these countries are mainly characterized by a multitude of small scale farmers scattered over a wide expanse of land area. Hence, these poorly employed people barely earn for their sustenance indicating a very low income. The agricultural sector has a potential to improve any nation's socioeconomic and industrial fabric because of the multifunctional nature of the sector. It has the potential to be the industrial and economic springboard from which the country's development can take off. Indeed, more often than not, agricultural activities are usually concentrated in the less developed rural areas where there is a critical need for rural transformation, redistribution, poverty alleviation and socioeconomic development, thus the poor rural unskilled individuals are ready to work with no basic education and at a minimum wage. Therefore, these reasons clearly justify the fact that employment and income have an inverse relationship in the case of low HDI countries.

The unexpected relationship between consumption and income in case of Medium HDI countries can be explained through the percentage of youth population. It is the highest (mean: 38.3 compared to the mean of High HDI countries as 25.7 and Low HDI countries as 15.0) among all the three categories and from Life Cycle Hypothesis, we can justify that the consumption and savings patterns of an individual are planned and calculated by them based both on the resources available to them over their lifetime, and on their current life stage.

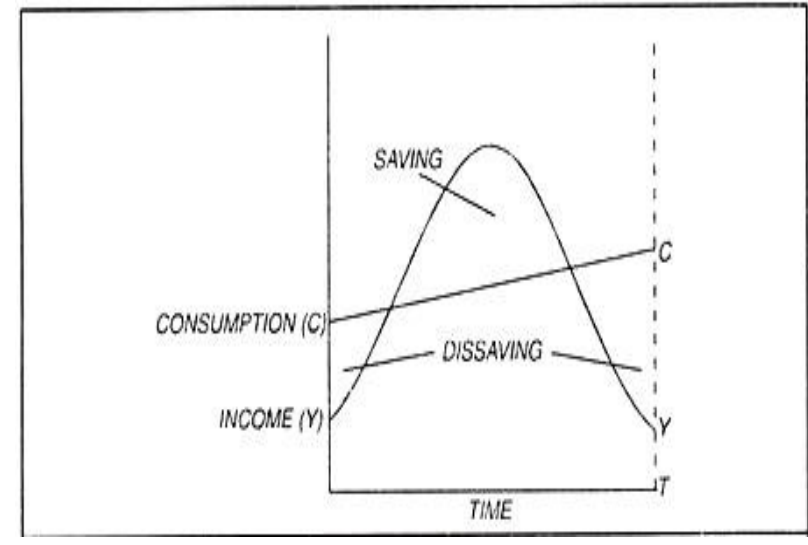

\section{Income And Consumption Over The Life Cycle}

In the developing country like India, where the population is so high young people tend to borrow to finance education and home purchases in the initial stage which act as a dissaving (shown in the graph above). In the middle age, these people earn and if due to increase in skill and productivity, their income increases per employed especially though, who have attained a higher respected designation in any firm or government job or, on the contrary, seeing the current scenario of employees being sacked from their jobs for cost cutting, these individuals consume less irrespective of their even high income and save more. Also paying off the debts that 


\section{International Journal of Advanced Multidisciplinary Scientific Research (IJAMSR) ISSN:2581-4281}

they had taken in the initial stages. Many individuals also consume less today, thinking about their future generations for whom they are more likely to save that will act as a stock of wealth for their children. After retirement or old age, these individuals draw out their savings or simply we can say that they deserve. However, even in their old age these elderly people may spend less and further save more. One reason may be they want to leave bequests to children and the other reason may be they are concerned about covering unpredictable expenses like health problems or living much more than an average life span, etc. Therefore, we can pen down that the Medium HDI countries with high youth population are more likely to follow life cycle hypothesis, thereby showing a negative relationship between income and consumption in these countries.

\section{Conclusion}

Numerous studies have emphasized on the importance of investment in human capital where the merit goes to the Nobel Laureates of economy like; Gary Becker, Theodore Schultz and James Heckman. The paper aims to present some of the results of studies of these Nobel Laureates, which focus on the necessity of investing in human capital, especially investment in education, even in very early childhood, then the investment in the training of workers for the establishment of labor productivity.

This paper estimates returns to education in India using a nationally representative survey, i.e. Human Development Report, and form a multiple regression model to significantly check whether education has a positive effect on the standard of living of an individual. There can be an end number of variables for measuring the standard of living, but here in this paper, we consider consumption, which is definitely one of the major reflectors of standard of living of any individual.

Thus, the theory goes as, an increase in education implies an increase in employment that further indicates the rise in income and then an increase in the consumption level. And in directly an increase in education is supposed to increase the consumption of an individual which in this paper is measuring the standard of living. However, after doing the correlation between these variables, hypothesis testing to check its significance and then running a multiple regression model on these variables with consumption (standard of living) as the dependent variable and education; employment; income and inequality in income as the independent variables, we found out that it is only in case of the High HDI countries that the theory already mentioned above proves to be true (all the required empirical results already shown in this paper) and all the relationship between all the required variables are positive. However, this is not found to be true in case of Medium and Low HDI countries. And after further exploratory research that was done, the major reasons for such result has already been discussed in the paper.

Hence, in brief, it can be said that investing in human capital, particularly in education is essential for sustainable economic development. However, higher education will lead to a high standard of living (especially consumption) depends mainly on the consumption pattern or consumption behavior of an individual. And, there is relatively little divergence in consumption patterns of a developed and developing or least developed countries, even as measures of income inequality have climbed in recent decades. 
Consider two societies: in the first society, some of the people are well-educated and earn consistently high salaries, while the others can only find low-paying work; in the second society, some earns a moderate salary on average but earnings bounce around significantly from year to year, perhaps due to a rise in uncertain work patterns and job opportunities; and some are even unemployed irrespective of their education level. Both of these societies would look very unequal based on measures of income inequality alone, but one of them seems considerably more egalitarian than the other. This is one of the reasons that some economists look to consumption data rather than income data as a better assessment of standard of living.

Therefore, as quoted by Aguiar and Bils (2015), "Rather than measure consumption inequality directly by summing household expenditures, we base our measure of consumption inequality on how richer versus poorer households allocate spending across goods."

When people make decisions about what to consume, and how much they want to borrow or save, they think not only about their income this year, but about how much savings they have accumulated and how much more they expect to earn over the rest of their lifetime. In this way, a person's consumption decisions in a given year can tell researchers more about her socioeconomic status than her income level alone, and might tell us more about how unequal a society really is.

\section{Policy Recommendations}

Education: the most powerful investment in our future

High HDI Countries:

1. Since all the developed countries are a part of High HDI countries and we have seen all positive relationships with education in the standard of living (here, consumption), hence they should continue with their ongoing policies to maintain such positive results. Their skilled workers, high productivity, development and innovative technology are the major reasons behind their high income and high consumption pattern. Thus, resulting in a high standard of living.

However, education is at the forefront when it comes to the public and the media. There are three major areas where these developed nations are working on for further enhancement of the education sector and their standard of living. These policies are:

i) Free childcare entitlement: The Government has doubled the free childcare allowance for working parents of three and four year olds from 15 to 30 hours per week from September, 2017.

ii) Fairer funding: The long-awaited National Funding Formula (NFF) for schools emerged in 2017, with resources being relocated from London and some other urban centers to schools in other parts 


\section{International Journal of} Advanced Multidisciplinary Scientific Research (IJAMSR) ISSN:2581-4281

of the country, in order to equalize perpupil funding across schools with similar intakes. The government has, however offered further targeted support for deprived areas in these developed nations through programs such as its Opportunity Areas scheme.

\section{Medium And Low HDI Countries:}

The Investment Case for Education and Equity calls for urgent action in these mediums and low HDI countries.

1) Government of these countries should allocate more resources to education, especially in the early grades;

2) More emphasis on allocating funds to the poorest areas that would target the poorest sections of the society

3) Should establish policies that would lead to skill enhancement and consequently increase the productivity level. This would result in the improvement of spending efficiency

4) Focus on improving the overall infrastructure, especially in the low HDI countries that would lay a foundation for more job creation.

5) Strengthen learning assessment systems and implement accountability measures that involve parents and communities.

However, Government has announced a slew of measures to be undertaken in the education sector. The key highlights are:
1) An 'Integrated B.Ed.' program will be started soon, with teacher training as the main focus

2) Rs.1 lakh crore to be invested over the next 4 years for a new drive to boost Research and Development

3) Tech to be the biggest driver in the education sector with increased digital intensity and a mission to move from Black board to digital boards.

There is no time to lose. Educated children are at the heart of healthy, productive and prosperous societies. If that is the future we want tomorrow, we must invest today.

\section{References}

1) Ando. A. and F. Modigliani, 1963. American Economics Review. Aggregate implicating and Test. The life cycle hypothesis of consumption.

2) Becker, G. S. 1962. "Investment in Human Capital: A Theoretical Analysis." Journal of Political Economy LXX:9-49.

3) Bowman, M. J., and C. A. Anderson.1963. "Concerning the Role of Education in Economic Development." In C. Geertz, ed., Old Societies and New States. New York: Free Press of Glencoe.

4) Blanchflower David G, Andrew J. Oswald. "WellBeing Over Time in Britain and the USA." NBER Working Paper No. 7487, Issued in January 2000

5) Cohen, Daniel and Marcelo Soto. 2007. "Growth and human capital: good data, good results." Journal of Economic Growth 12:51-76

6) Foster, Andrew D \& Rosenzweig, Mark R, 1996. "Technical Change and Human-Capital Returns and Investments: Evidence from the Green Revolution," American Economic Review, American Economic Association, vol. 86(4), pages 931-953, September. 
https://doi.org/10.31426/ijamsr.2018.1.4.212

I J A M S R

International Journal of

Advanced Multidisciplinary Scientific Research (IJAMSR) ISSN:2581-4281

7) Harmon, Colm, Hessel Oosterbeek, and Ian Walker. 2003. "The Returns to Education: Microeconomics." Journal of Economic Surveys, 17:2, pp. 115-55.

8) Michael, Robert T.: The Effect of Education on Efficiency in Consumption, National Bureau of Economic Research, New York, 1972.

9) Psacharopoulos, George and Harry Anthony Patrions. 2004. "Returns to Investment in Education: A Further Update." Education Economics, 12:2, pp. $111-34$.

10) Tilak, Jandhyala B.G. 1987. The Economics of Inequality in Education. New Delhi: Sage Publications.

11) Human Development Reports: 2015.

12) World Bank Reports: 2015 